\title{
Intestinal obstruction due to pneumatosis intestinalis
}

\author{
Aled W. Jones \\ M.B., Ch.B., D.Path. \\ Assistant Lecturer
}

\author{
F. M. Cole \\ M.D.
}

Lecturer

\section{Department of Pathology, University of Manchester}

Pneumatosis intestinalis is a condition characterized by the presence of numerous gas-filled cysts, most commonly found in the sub-serosa of the wall of the small intestine. Nearly 300 cases have been described and the literature of the adult cases has been reviewed by Koss (1952), and those occurring in childhood and infancy by MacKenzie (1951). Although the cysts are frequently associated with other intestinal lesions, they themselves are usually symptomless and rarely give rise to complications. Those complications which have been described include pneumo-peritoneum and intestinal obstruction. Cysts can cause obstruction in several ways, one of which is by the formation of fibrous bands and strictures in relation to them, The following report describes such a case.

\section{Case report}

A retired docker, aged 68, was seen with a 3-week history of abdominal pain. He had had no bowel action for 5 days and had only passed a small quantity of flatus. He gave a 40-year history of dyspepsia for which he had been given antacids.
Four years previously he had a perforated ulcer repaired surgically; no note was made at the time of any other lesion within the abdominal cavity.

Three years prior to admission he had a haematemesis requiring blood transfusion. A barium meal at this time suggested a certain amount of pyloric hold-up which was probably due to pylorospasm caused by the duodenal ulcer; a second barium meal 1 year later showed no delay in gastric emptying.

For 6 months prior to the present admission he had, in addition to his ulcer pain, suffered a second type of abdominal pain. This pain was situated in the lower abdomen; it was intermittent, lasting up to 1 week at a time, colicky in type and unrelieved by antacids. It was getting progressively more severe. For 3 weeks he had been vomiting intermittently but for the few days prior to hospitalization he had vomited everything taken by mouth, but this did not relieve the pain. The vomitus consisted mainly of digested food and contained no blood.

On examination he was dehydrated and hiccoughed constantly. The abdomen was distended, tympanitic, and the umbilicus was everted.

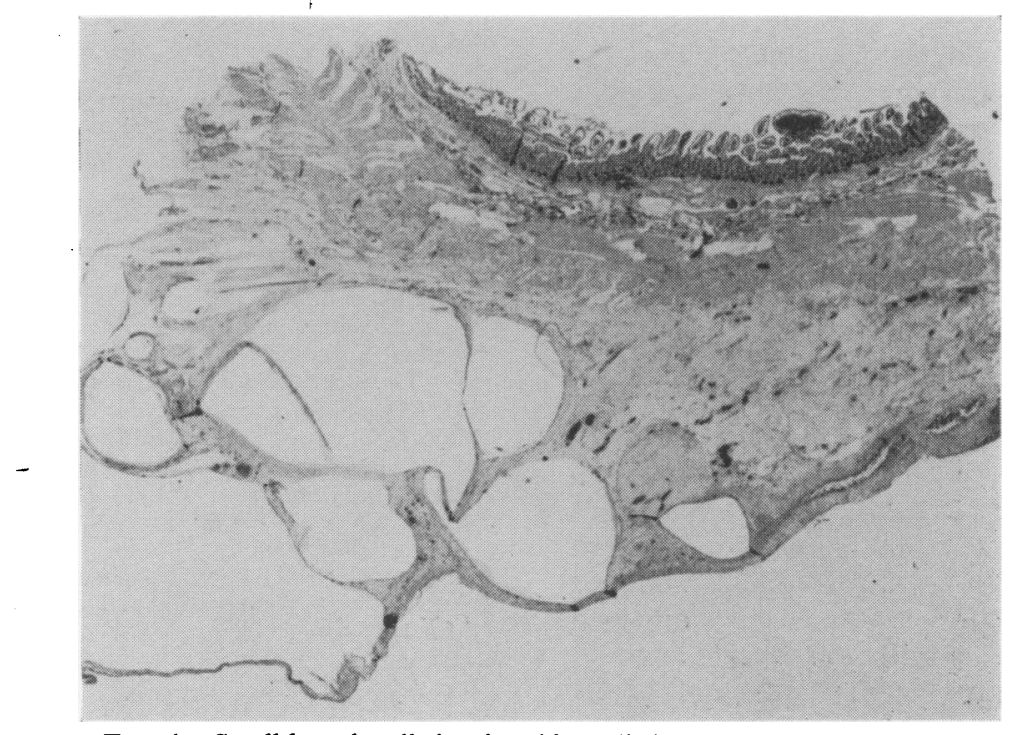

FIG. 1. Small bowel wall showing thin-walled cyst, mainly in sub-serosal position. H \& E, $\times 5 \cdot 5$. 
Distended coils of small intestine were prominent but no peristalsis was seen.

A clinical diagnosis of small bowel intestinal obstruction was made and a laparotomy carried out the same day. The small bowel was grossly distended and the peritoneal cavity contained a small amount of clear straw-coloured fluid. The obstruction was due to a thick fibrous band situated $60 \mathrm{~cm}$ proximal to the ileo-caecal junction. The ileum at the point of constriction was kinked at a right angle and showed many sub-serosal gas-filled cysts which involved $7 \mathrm{~cm}$ of ileum proximal to the fibrous band. The cysts were thin-walled and measured $0.5-1 \mathrm{~cm}$ in diameter (Fig. 1). They contained no fluid and burst like balloons under pressure. No cysts were seen elsewhere. A $17 \mathrm{~cm}$ length of ileum was resected and an end-to-end anastomosis performed.

Twenty-three days later he was re-admitted in a shocked state with generalized peritonitis. A laparotomy revealed a perforated gastric ulcer situated high on the greater curvature $8 \mathrm{~cm}$ from the cardio-oesophageal junction. It was noted that the pylorus was a little thickened and the lumen narrowed. Because of the latter finding, the presence of a large dilated stomach and the known duodenal ulcer, a gastro-enterostomy was performed as well as repair of the perforation. Despite resuscitative measures the patient remained shocked, developed a left femoral artery thrombosis and died on the second post-operative day.

\section{Microscopy of the surgical specimen}

The walls of the cysts consist of dense hyaline fibrous tissue. They are lined by prominent endothelial cells. These cells vary greatly in size and are often multi-nuclear (Fig. 2). In other areas the endothelial lining is absent. The tissue surrounding the cysts shows a mild chronic non-specific inflammation.

Necropsy revealed a large chronic duodenal ulcer. The repaired gastric ulcer and the gastroenterostomy were intact. Recent thrombosis of the left femoral artery was confirmed. The small intestine anastomosis was intact; no remaining gas cysts were found.

\section{Discussion}

Pneumatosis intestinalis is a member of a larger group of conditions characterized by the presence of gas cysts in tissue, called cystic pneumatosis (Colquhoun, 1965). Cystic pneumatosis must be differentiated from interstitial emphysema in which the gas is in a non-cystic form, and gas which is produced by organisms.

Apart from the gut, gas cysts have been described in the mesentery, retroperitoneal tissue, diaphragm (Koss, 1952), in the vagina (Bender \& Jeffcoate, 1950; Abell, 1958; Hoffman \& Grundfest, 1959), and rarely in the stomach (Baumann-Schenker, 1939; Keyting et al., 1961). In the majority of cases the bowel wall alone has been involved, but in a minority of cases lesions have occurred at other sites also. In the gastro-intestinal tract the locations of the cysts are, in decreasing order of frequency, the jejunum and ileum, colon (pneumatosis coli), caecum, duodenum and stomach.

Many diverse theories concerning the aetiology of intestinal gas cysts have been postulated, but only one-the mechanical theory-has been supported by experimental studies, and most authors have

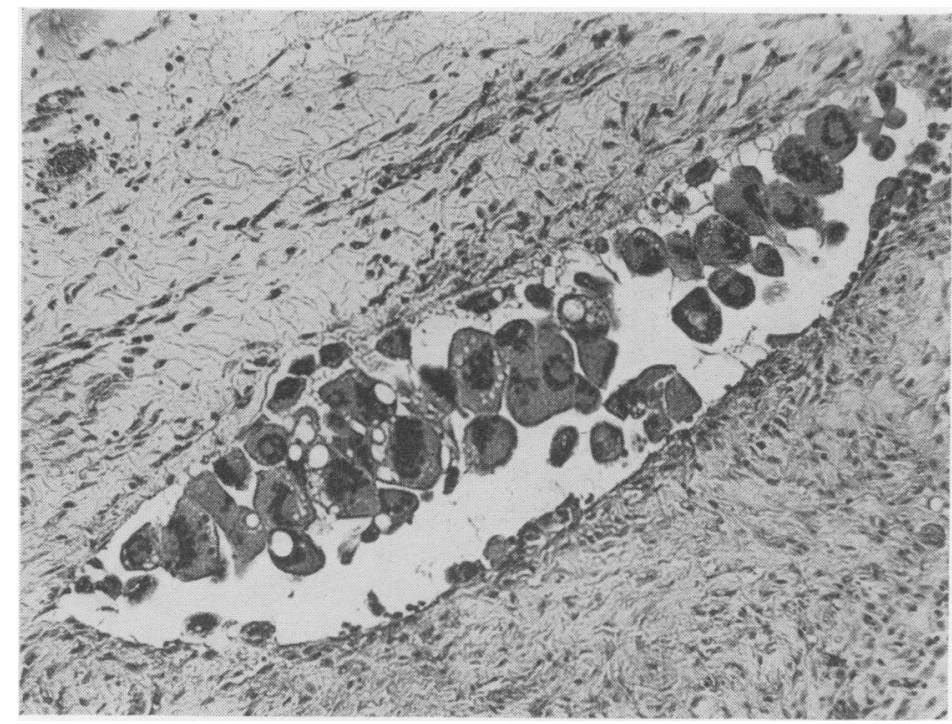

FIG. 2. Small cyst lined by endothelial cells of varying size, the majority of which are multi-nucleate. H \& E, $\times 72$. 
favoured this view. Many cases are explained by intraluminal gas being forced through a mucosal tear and tracking along tissue planes of the gut wall, although Koss felt that the gas passed along lymphatic vessels. This is supported by the fact that a large number of cases of pneumatosis intestinalis are associated with peptic ulcers complicated by pyloric stenosis or some other gastrointestinal tract lesion, for it is postulated that the obstructive element with its consequent increase in intra-luminal pressure is responsible for penetration of air through the mucosa. Koss classified these cases as secondary, and those without associated lesions as primary. Doub \& Shea (1960) and Keyting et al. (1961) showed that many cases of pneumatosis intestinalis were associated with chronic pulmonary disease, and the latter authors suggested that coughing gives rise to alveolar rupture and pneumo-mediastinum. The air then tracks along the walls of the aortic and mesenteric vessels to the bowel. Keyting et al. (1961), using experimental animals and fresh cadavers, demonstrated that air injected into the mediastinum took this path to the small bowel. Consequently they suggested that the division of the disease into primary and secondary forms should be abandoned, as they considered all cases to be secondary either to an ulcerating or obstructive intestinal lesion, to trauma following sigmoidoscopy or biopsy, or to chronic pulmonary disorders.

In general, most cases of pneumatosis intestinalis are symptomless, and are discovered either on routine radiology, incidentally at laparotomy, or at autopsy. Complications, however, do arise and include pneumo-peritoneum, volvulus, intussusception and intestinal obstruction. The latter has been described as occurring in one of three ways:

(1) The encroachment of submucosal cysts into the lumen of the bowel (Thoma \& Henningar, 1952; Meikle, 1965). This is the least common method of obstruction, because the cysts are not usually submucosal in position, and rarely elevate the mucosa to such an extent as to interfere with intestinal transit.

(2) Large extrinsic masses of cysts may compress the bowel and cause obstruction (Parson \& Parson, 1948). This event is also uncommon as the cysts do not often attain such large dimensions, and are usually freely movable.
(3) Adhesions form in relation to the cysts and adjoining organs, and constrict the bowel. This is the mode of $r$ bstruction in the present case, and it has been reported on four previous occasions (Winands, 1898; Steindl, 1921; Gazin et al., 1949; Koss, 1952).

Pneumatosis intestinalis is a rare and usually symptomless condition; nevertheless it can on occasion give rise to an acute abdominal emergency. Attention is drawn to the fact that obstruction due to fibrous bands can occur; the signs and symptoms of which might easily be confused with those of other intestinal lesions with which the condition is often associated. This difficulty can in many cases be overcome by an awareness of the condition and careful examination of a routine radiograph of the abdomen.

\section{References}

Abell, M.R. (1958) Cervicocolpitis (vaginitis) emphysematosa. Surg. Gynec. Obstet. 107, 631.

Baumann-Schenker, R. (1939) Uber Pneumatosis cystoides ventriculi et jejuni. Acta radiol. scand. 20, 365.

Bender, S. \& Jefrcoate, T.N.A. (1950) Vaginitis emphysematosa. J. Obstet. Gynaec. Br. Commonw. 57, 432.

Colquhoun, J. (1965) Intramural gas in hollow viscera. Clin. Radiol. 16, 71.

Doub, H.P. \& SHEA, J.J. (1960) Pneumatosis cystoides intestinalis. J. Amer. med. Ass. 172, 1238.

Gazin, A.I., Brooke, W.S., Lerner, H.H. \& Price, R.B. (1949) Pneumatosis intestinalis; roentgen diagnosis andō surgical management. Amer. J. Surg. 77, 563.

Hoffman, D.B. \& Grundfest, P. (1959) Vaginitis emphysematosa. A case report. Amer. J. Obstet. Gynec. 78, 428.

Keyting, W.S., McCarver, R.R., Kovarik, J.L. \& DAywitt, A.L. (1961) Pneumatosis intestinalis: A new concept. Radiology, 76, 733.

Koss, L.G. (1952) Abdominal gas cysts. (Pneumatosis cystoides intestinorum hominis.) An analysis with report of a case and critical review of the literature. Arch. Path. $53,523$.

MacKenzie, E.P. (1951) Pneumatosis intestinalis. Review of the literature with report of 13 cases. Pediatrics, 7, 537.

Meikle, G. (1965) A case of pneumatosis coli. J. roy. Coll. Surg. Edinb. 11, 65.

Parson, R.M. \& Parson, W.B. (1948) Cystic intestinal pneumatosis. Can. med. Ass. J. 58, 71.

STEINDL, H. (1921) Zur Kenntris der Gaszystenbildung am menschlichen Darm und ihrer Entstehungsweire. Dsch. $Z$. Chir. 163, 44.

Thoma, G.W. \& Henniger, G.R. (1952) Pneumatosis intestinalis with chronic intestinal obstruction. Report of a case. Amer. J. clin. Path. 22, 765.

Winands, M. (1898) Uber einen Fall von Gascysten in der Darmwand und in peritonitischen Pseudomembranen. Beitr. path. Anat. 17, 38. 